Pacific Journal of Mathematics

COMMUTANTS OF QUASISIMILAR SUBNORMAL
OPERATORS Marc Raphael 


\title{
COMMUTANTS OF QUASISIMILAR SUBNORMAL OPERATORS
}

\author{
MARC RAPHAEL
}

\begin{abstract}
In this paper it is shown if two rationally cyclic subnormal operators are quasisimilar, then they have naturally isomorphic commutants.
\end{abstract}

1. Introduction. An operator $S$ on a Hilbert space $\mathscr{H}$ is subnormal if there is a Hilbert space $\mathscr{K}$ containing $\mathscr{H}$ and a normal operator $N$ on $\mathscr{K}$ such that $N \mathscr{H} \subset \mathscr{H}$ and $S=N \mid \mathscr{H}$ (the restriction of $N$ to $\mathscr{H}$ ). The weak* topology on $\mathscr{B}(\mathscr{H})$ is the topology $\mathscr{B}(\mathscr{H})$ has as the Banach space dual of $\mathscr{B}_{1}(\mathscr{H})$, the trace class operators [4].

An operator $S$ in $\mathscr{B}(\mathscr{H})$ is rationally cyclic if there is an $e$ in $\mathscr{H}$ such that $\{r(S) e: r \in \operatorname{Rat} \sigma(S)\}$ is dense in $\mathscr{H}$. (Notation: Rat $\sigma(S)$ is the set of rational functions with poles off $\sigma(S)$, the spectrum of $S$; and $e$ is called a rationally cyclic vector for $S$.) The commutant of $S$ is the weak* closed subalgebra of $\mathscr{B}(\mathscr{H})$ defined by: $\{S\}^{\prime}=\{A \in \mathscr{B}(\mathscr{H}): A S=S A\}$.

A measure $\mu$ is always a compactly supported, positive, regular Borel measure on the complex plane, $\mathbf{C}$. If $S$ is a rationally cyclic subnormal operator then there exist a measure $\mu$ and a compact set $K$ containing the support of $\mu$ such that $S$ is unitarily equivalent to $S(K, \mu)$, the operator of multiplication by $z$ on $R^{2}(K, \mu)=$ the closure of Rat $K$ in $L^{2}(\mu)$ [4]. Yoshino's Theorem [4] states that the map from $R^{2}(K, \mu) \cap L^{\infty}(\mu)$ onto $\{S(K, \mu)\}^{\prime}$ given by $\phi \mapsto \phi(S(K, \mu))=$ multiplication by $\phi$ is an isometric isomorphism and a weak* homeomorphism. For $f$ in $L^{\infty}(\mu),\|f\|_{\mu}$ denotes the $\mu$-essential supremum of $f$.

If $\mathscr{H}_{1}$ and $\mathscr{H}_{2}$ are Hilbert spaces, a bounded linear operator $X$ : $\mathscr{H}_{1} \rightarrow \mathscr{H}_{2}$ is said to be quasi-invertible if it is injective and has dense range. If $S_{j} \in \mathscr{B}\left(\mathscr{H}_{j}\right)(j=1,2)$, then $S_{1}$ is quasisimilar to $S_{2}$ if there are quasi-invertible operators $X_{21}: \mathscr{H}_{1} \rightarrow \mathscr{H}_{2}$ and $X_{12}: \mathscr{H}_{2} \rightarrow \mathscr{H}_{1}$ such that $X_{21} S_{1}=S_{2} X_{21}$ and $X_{12} S_{2}=S_{1} X_{12}$. Unlike similarity, quasisimilar operators need not have equal spectra [5], though their spectra cannot be disjoint [5]. However, quasisimilar subnormal operators must have equal spectra $[1,2,3]$, and rationally cyclic ones have the same approximate point spectra [6]. 
2. The main result. It is proved in [3] that the weak* algebras generated by quasisimilar subnormal operators are isometrically isomorphic and weak* homeomorphic via a natural map. Theorem 1 shows the existence of a similar map between properly larger algebras, but carries the additional hypothesis that the subnormal operators be rationally cyclic. Some restrictive hypothesis on the subnormal operators is necessary since there is an example of an irreducible subnormal operator similar to a reducible one (p. 276, [4]).

THEOREM 1. If $S_{1}$ and $S_{2}$ are quasisimilar rationally cyclic subnormal operators, then there exists an isometric isomorphism and weak ${ }^{*}$ homeomorphism $\Lambda:\left\{S_{1}\right\}^{\prime} \rightarrow\left\{S_{2}\right\}^{\prime}$ such that $\Lambda\left(r\left(S_{1}\right)\right)=r\left(S_{2}\right)$ for all $r$ in Rat $\sigma\left(S_{1}\right)$.

Theorem 1 answers an open question posed on page 225 of [4]. Its proof follows from several preliminary results and is postposed until the end of this paper.

The following proposition is essentially the same as Proposition 4.1 of [3]. Its statement and proof for the rationally cyclic case are included here since there will be need for recourse to them later.

Proposition 2 (Conway, [4]). Suppose $S_{1}$ and $S_{2}$ are rationally cyclic quasisimilar subnormal operators. Then, for $i=1,2$, there exist measures $\mu_{\imath}$ such that $S_{i}$ is unitarily equivalent to $S\left(\sigma\left(S_{i}\right), \mu_{\imath}\right)$, constants $c_{i}$, and $\phi$ in $R^{2}\left(\sigma\left(S_{1}\right), \mu_{1}\right) \cap L^{\infty}\left(\mu_{1}\right)$ such that:

(a) $\left\{\phi r: r \in \operatorname{Rat} \sigma\left(S_{1}\right)\right\}$ is dense in $R^{2}\left(\sigma\left(S_{1}\right), \mu_{1}\right)$;

(b) for every $r$ in Rat $K$,

$$
c_{2} \int|\phi|^{2}|r|^{2} d \mu_{1} \leq \int|r|^{2} d \mu_{2} \leq c_{1} \int|r|^{2} d \mu_{1} .
$$

Proof. Let $Y_{i j}: \mathscr{H}_{j} \rightarrow \mathscr{H}_{i}$ be quasi-invertible operators such that $Y_{i j} S_{J}=S_{i} Y_{i j}$. If $e_{1}$ is a rationally cyclic vector for $S_{1}$, then it follows that $e_{2}=Y_{21} e_{1}$ is a rationally cyclic vector for $S_{2}$. Choose measure $\mu_{j}$ and isomorphisms $U_{J}: \mathscr{H}_{J} \rightarrow R^{2}\left(\sigma\left(S_{j}\right), \mu_{j}\right)$ with $U_{J} e_{j}=1$ and $U_{J} S_{j} U_{j}^{-1}=$ $S\left(\sigma\left(S_{J}\right), \mu_{j}\right)$ (p. $\left.146[4]\right)$. Let $X_{l j}=U_{l} Y_{\imath J} U_{J}^{-1}$. So $X_{i j}: R^{2}\left(\sigma\left(S_{J}\right), \mu_{J}\right) \rightarrow$ $R^{2}\left(\sigma\left(S_{i}\right), \mu_{l}\right)$ is quasi-invertible. Moreover, it is straightforward to verify that $X_{i j} S\left(\sigma\left(S_{J}\right), \mu_{j}\right)=S\left(\sigma\left(S_{l}\right), \mu_{i}\right) X_{l j}$.

If $r \in \operatorname{Rat} \sigma\left(S_{1}\right)$, then

$$
\begin{aligned}
X_{21} r & =X_{21} r\left(S\left(\sigma\left(S_{1}\right), \mu_{1}\right)\right) 1=r\left(S\left(\sigma\left(S_{2}\right), \mu_{2}\right)\right) X_{21} 1 \\
& =r\left(S\left(\sigma\left(S_{2}\right), \mu_{2}\right)\right) U_{2} Y_{21} e_{1}=r\left(S\left(\sigma\left(S_{2}\right), \mu_{2}\right)\right) 1=r .
\end{aligned}
$$

If $c_{1}=\left\|X_{21}\right\|^{2}$, this shows that $\int|r|^{2} d \mu_{2} \leq c_{1} \int|r|^{2} d \mu_{1}$. 
To find the constant $c_{2}$, notice that $X_{12} X_{21}$ commutes with $S\left(\sigma\left(S_{1}\right), \mu_{1}\right)$. By Yoshino's Theorem there exists $\phi$ in $R^{2}\left(\sigma\left(S_{1}\right), \mu_{1}\right) \cap$ $L^{\infty}\left(\mu_{1}\right)$ such that $X_{12} X_{21} f=\phi f$ for every $f$ in $R^{2}\left(\sigma\left(S_{1}\right), \mu_{1}\right)$. Hence for $r$ in Rat $\sigma\left(S_{2}\right), \phi r=X_{12} X_{21} r=X_{12} r$. Let $c_{2}=\left\|X_{12}\right\|^{-2}$.

The next two results are the keys to establishing Theorem 1.

PROPOSITION 3. If $S_{1}$ and $S_{2}$ are similar rationally cyclic subnormal operators, then the conclusion of Theorem 1 is valid.

Proof. Let $X: \mathscr{H}_{1} \rightarrow \mathscr{H}_{2}$ be an invertible bounded linear operator such that $S_{2}=X S_{1} X^{-1}$. If $A \in\left\{S_{1}\right\}^{\prime}$ it is easy to see that $X A X^{-1} \in\left\{S_{2}\right\}^{\prime}$. Define $\Lambda:\left\{S_{1}\right\}^{\prime} \rightarrow\left\{S_{2}\right\}^{\prime}$ by $\Lambda A=X A X^{-1}$. It is easy to verify that $\Lambda$ is onto $\left\{S_{2}\right\}^{\prime}$ and an algebra isomorphism. By Yoshino's Theorem $A$ and $\Lambda A$ are subnormal operators. Since $A$ and $\Lambda A$ are similar, they have the same spectra; hence $\|A\|=\|\Lambda A\|$.

Suppose $\left\{A_{\alpha}\right\} \subset\left\{S_{1}\right\}^{\prime}$ is a net converging weak* to $A$ in $\left\{S_{1}\right\}^{\prime}$. Let $T \in \mathscr{B}_{1}\left(\mathscr{H}_{2}\right)$. Then

$$
\begin{aligned}
\operatorname{tr}\left(T \Lambda A_{\alpha}\right) & =\operatorname{tr}\left(T X A_{\alpha} X^{-1}\right)=\operatorname{tr}\left(X^{-1} T X A_{\alpha}\right) \\
& \rightarrow \operatorname{tr}\left(X^{-1} T X A\right)=\operatorname{tr}\left(T X A X^{-1}\right)=\operatorname{tr}(T \Lambda A) .
\end{aligned}
$$

This shows $\Lambda$ is weak* continuous. Since $\Lambda\left(r\left(S_{1}\right)\right)=r\left(S_{2}\right)$ for all $r$ in Rat $\sigma\left(S_{1}\right)$, the proof is complete.

Simplification Theorem 4. For $i=1,2$ let $\mu_{i}$ be a measure and $K$ be a compact subset of $\mathbf{C}$ such that the support of $\mu_{i}$ is contained in $K$. Suppose $\phi \in R^{2}\left(K, \mu_{1}\right) \cap L^{\infty}\left(\mu_{1}\right)$ and $\{\phi r: r \in$ Rat $K\}$ is dense in $R^{2}\left(K, \mu_{1}\right)$.

If the bounded linear operators $X_{21}^{1}: R^{2}\left(K, \mu_{1}\right) \rightarrow R^{2}\left(K, \mu_{2}\right)$ and $X_{12}^{\phi}$ : $R^{2}\left(K, \mu_{2}\right) \rightarrow R^{2}\left(K, \mu_{1}\right)$ are quasi-invertible and satisfy

(a) $X_{21}^{1} r=r$ for all $r$ in Rat $K$

(b) $X_{12}^{\phi} r=\phi r$ for all $r$ in Rat $K$, then $\Lambda: R^{2}\left(K, \mu_{1}\right) \cap L^{\infty}\left(\mu_{1}\right) \rightarrow R^{2}\left(K, \mu_{2}\right) \cap L^{\infty}\left(\mu_{2}\right)$, defined by

$$
\Lambda f=X_{21}^{1} f \text {, }
$$

is an isometric isomorphism and a weak* homeomorphism.

The author does not know if the map in Theorem 1 is uniquely determined by the condition that $r\left(S_{1}\right) \mapsto r\left(S_{2}\right)$ for all $r$ in Rat $\sigma\left(S_{1}\right)$. Couched in terms of the Simplification Theorem, it is easy to see that the aforementioned map is unique if the following query has an affirmative answer. 
If $\Lambda: R^{2}(K, \mu) \cap L^{\infty}(\mu) \rightarrow R^{2}(K, \mu) \cap L^{\infty}(\mu)$ is an isometric isomorphism and a weak* homeomorphism that is the identity map when restricted to Rat $K$, then must $\Lambda$ be the identity map on $R^{2}(K, \mu) \cap$ $L^{\infty}(\mu)$ ?

Two lemmas are now stated and proved. They are used in the proof of the Simplification Theorem.

Lemma 5. Assume the hypothesis of Simplification Theorem 4 with the exception that $X_{21}^{1}$ need not be bounded on Rat $K$. Then for all $f$ in $R^{2}\left(K, \mu_{2}\right) \cap L^{\infty}\left(\mu_{2}\right)$ and all non-negative integers $n$,

$$
X_{12}^{\phi} f^{n}=\left(X_{12}^{\phi} f\right)^{n} \cdot \phi^{1-n} \quad \mu_{1}-\text { a.e. }
$$

Consequently, $X_{12}^{\phi}$ maps $R^{2}\left(K, \mu_{2}\right) \cap L^{\infty}\left(\mu_{2}\right)$ into $R^{2}\left(K, \mu_{1}\right) \cap L^{\infty}\left(\mu_{1}\right)$ and $\left\|X_{12}^{\phi} f\right\|_{\mu_{1}} \leq\|\phi\|_{\mu_{1}}\|f\|_{\mu_{2}}$.

Proof. Equation (6) will be shown by induction on $n$. If $n=1$ then (6) certainly holds. Suppose (6) is true for $1 \leq k \leq n$. To show that (6) holds for $k=n+1$, let $f \in R^{2}\left(K, \mu_{2}\right) \cap L^{\infty}\left(\mu_{2}\right)$ and let $\left\{r_{s}\right\}$ and $\left\{q_{m}\right\}$ be sequences in Rat $K$ such that $r_{s} \rightarrow f$ in $L^{2}\left(\mu_{2}\right)$ and $q_{m} \rightarrow f^{n}$ in $L^{2}\left(\mu_{2}\right)$. Then

$$
\begin{aligned}
X_{12}^{\phi} f^{n+1} & =\lim _{m \rightarrow \infty} X_{12}^{\phi}\left(f q_{m}\right)=\lim _{m \rightarrow \infty}\left\{X_{12}^{\phi}\left(\lim _{s \rightarrow \infty} r_{s} q_{m}\right)\right\} \\
& =\lim _{m \rightarrow \infty}\left\{q_{m}\left(\lim _{s \rightarrow \infty} X_{12}^{\phi} r_{s}\right)\right\}=\phi^{-1}\left(\lim _{m \rightarrow \infty} X_{12}^{\phi} q_{m}\right)\left(X_{12}^{\phi} f\right) \\
& =\phi^{-1}\left(X_{12}^{\phi} f^{n}\right)\left(X_{12}^{\phi} f\right)=\left(X_{12}^{\phi} f\right)^{n+1} \cdot \phi^{-n},
\end{aligned}
$$

where all limits are taken in the appropriate $L^{2}$-space and the induction hypothesis is used to obtain the next to last equality. This substantiates (6).

In order to obtain the norm estimate involving $X_{12}^{\phi}$ let $f \in R^{2}\left(K, \mu_{2}\right)$ $\cap L^{\infty}\left(\mu_{2}\right)$ such that $\|f\|_{\mu_{2}}<1$. Since $f^{n} \rightarrow 0$ in $L^{2}\left(\mu_{2}\right)$ and $X_{12}^{\phi}$ is bounded, it follows from (6) that

$$
\left\|X_{12}^{\phi} f^{n}\right\|_{2}^{2}=\int\left|X_{12}^{\phi} f\right|^{2 n}|\phi|^{2-2 n} d \mu_{1} \rightarrow 0
$$

as $n \rightarrow \infty$. Hence $\left|X_{12}^{\phi} f\right| \leq|\phi| \mu_{1}$-a.e.; so $\left\|X_{12}^{\phi} f\right\|_{\mu_{1}} \leq\|\phi\|_{\mu_{1}}$. Since $\|f\|_{\mu_{2}}$ $<1$, it follow easily that $\left\|X_{12}^{\phi} f\right\|_{\mu_{1}} \leq\|\phi\|_{\mu_{1}}\|f\|_{\mu_{2}}$ for all $f$ in $R^{2}\left(K, \mu_{2}\right) \cap$ $L^{\infty}\left(\mu_{2}\right)$. 
LEMMA 7. Assume the hypothesis and notation of Simplification Theorem 4. Then $\Lambda$ is an isometry on $R^{2}\left(K, \mu_{1}\right) \cap L^{\infty}\left(\mu_{1}\right)$, and $X_{21}^{1}(f g)=$ $\left(X_{21}^{1} f\right)\left(X_{21}^{1} g\right)$ whenever $f \in R^{2}\left(K, \mu_{1}\right) \cap L^{\infty}\left(\mu_{1}\right)$ and $g \in R^{2}\left(K, \mu_{1}\right)$.

Proof. Let $\left\{g_{n}\right\}$ be a sequence in Rat $K$ such that $g_{n} \rightarrow g$ in $L^{2}\left(\mu_{1}\right)$. Then

$$
\begin{aligned}
X_{21}^{1}\left(f g_{n}\right) & =X_{21}^{1} g_{n}\left(S\left(K, \mu_{1}\right)\right) f=g_{n}\left(S\left(K, \mu_{2}\right)\right) X_{21}^{1} f \\
& =\left(X_{21}^{1} g_{n}\right)\left(X_{21}^{1} f\right) .
\end{aligned}
$$

Letting $n \rightarrow \infty$ shows that $X_{21}^{1}(f g)=\left(X_{21}^{1} f\right)\left(X_{21}^{1} g\right)$.

It follows from Lemma 5 with $\phi=1$ that $\left\|X_{21}^{1} f\right\|_{\mu_{2}} \leq\|f\|_{\mu_{1}}$ when $f \in R^{2}\left(K, \mu_{1}\right) \cap L^{\infty}\left(\mu_{1}\right)$. To show the desired reverse inequality, it may be assumed that $\left\|X_{21}^{1} f\right\|_{\mu_{2}}<1$ and $\|\phi\|_{\mu_{1}}=1$.

Let $\left\{r_{s}\right\}$ be a sequence in Rat $K$ such that $r_{s} \rightarrow f$ in $L^{2}\left(\mu_{1}\right)$. Then

$$
\left(X_{12}^{\phi} X_{21}^{1}\right)(f)=\lim _{s \rightarrow \infty}\left(X_{12}^{\phi} X_{21}^{1}\right)\left(r_{s}\right)=\lim _{s \rightarrow \infty} \phi r_{s}=\phi f,
$$

where all limits are in $L^{2}\left(\mu_{1}\right)$. So, for $n \geq 1$, it follows easily from (6) that

$$
X_{12}^{\phi}\left(X_{21}^{1} f\right)^{n}=\phi f^{n} \quad \mu_{1} \text {-a.e. }
$$

Since, by the last part of Lemma $5,\left\|X_{12}^{\phi}\left(X_{21}^{1} f\right)^{n}\right\|_{\mu_{1}} \leq\left\|\left(X_{21}^{1} f\right)^{n}\right\|_{\mu_{2}} \rightarrow 0$ as $n \rightarrow \infty$, it must be that $\|f\|_{\mu_{1}} \leq 1$. This completes the proof of Lemma 7 .

Proof of Simplification Theorem 4. By Lemma 7 and the Krein-Smulian Theorem, it suffices to show $\Lambda$ is onto $R^{2}\left(K, \mu_{2}\right) \cap L^{\infty}\left(\mu_{2}\right)$ and weak* continuous. By the proof of Proposition 2 it is possible to do the following: choose measures $\nu_{i}(i=1,2)$ so that if $T_{i}=S\left(K, \nu_{l}\right)$ and $S_{i}=S\left(K, \mu_{i}\right)$, then $S_{i}$ and $T_{i}$ are unitarily equivalent; and the operators defined by

$$
\begin{gathered}
Y_{12}^{1}: R^{2}\left(K, \nu_{2}\right) \rightarrow R^{2}\left(K, \nu_{1}\right) \\
r \mapsto r, \text { and } \\
Y_{21}^{\lambda}: R^{2}\left(K, \nu_{1}\right) \rightarrow R^{2}\left(K, \nu_{2}\right) \\
r \mapsto \lambda r
\end{gathered}
$$

are quasi-invertible. (Here $\lambda$ is a fixed member of $R^{2}\left(K, \nu_{2}\right) \cap L^{\infty}\left(\nu_{2}\right)$ and $r \in$ Rat $K$.)

In order to prove that $\Lambda$ is onto $R^{2}\left(K, \mu_{2}\right) \cap L^{\infty}\left(\mu_{2}\right)$ it is shown that $X_{21}^{1} Y f=f$ for all $f$ in $R^{2}\left(K, \mu_{2}\right) \cap L^{\infty}\left(\mu_{2}\right)$, where $Y=I_{1} Y_{12}^{1} I_{2}$ and $I_{1}$ : $R^{2}\left(K, \nu_{1}\right) \cap L^{\infty}\left(\nu_{1}\right) \rightarrow R^{2}\left(K, \mu_{1}\right) \cap L^{\infty}\left(\mu_{1}\right), I_{2}: R^{2}\left(K, \mu_{2}\right) \cap L^{\infty}\left(\mu_{2}\right) \rightarrow$ $R^{2}\left(K, \nu_{2}\right) \cap L^{\infty}\left(\nu_{2}\right)$ are the "identity" maps in the proof of Proposition 3.

Since $S_{1}$ and $T_{1}$ are unitarily equivalent operators there exist an isomorphism $V: R^{2}\left(K, \nu_{1}\right) \rightarrow R^{2}\left(K, \mu_{1}\right)$ and $\Psi \in R^{2}\left(K, \mu_{1}\right)$ such that 
$V r=\Psi r$ for all $r$ in Rat $K$. Given $f$ in $R^{2}\left(K, \mu_{2}\right) \cap L^{\infty}\left(\mu_{2}\right)$ let $\left\{r_{s}\right\}$ be a sequence in Rat $K$ such that

$$
\begin{array}{ll}
r_{s} \rightarrow f=I_{2} f \text { in } L^{2}\left(\nu_{2}\right) & \text { and } \nu_{2} \text {-a.e., and } \\
r_{s} \rightarrow Y_{12}^{1} I_{2} f \text { in } L^{2}\left(\nu_{1}\right) & \text { and } \nu_{1} \text {-a.e. }
\end{array}
$$

Then,

$$
\begin{aligned}
{\left[X_{21}^{1} \Psi\right]\left[X_{21}^{1}\left(I_{1} Y_{12}^{1} I_{2} f\right)\right] } & =X_{21}^{1}\left[\Psi\left(I_{1} Y_{12}^{1} I_{2} f\right)\right] \\
& =\lim _{s \rightarrow \infty}\left[X_{21}^{1} V r_{s}\right]=\lim _{s \rightarrow \infty} X_{21}^{1}\left(\Psi r_{s}\right) \\
& =\lim _{s \rightarrow \infty}\left(X_{21}^{1} \Psi\right)\left(X_{21}^{1} r_{s}\right)=\left(X_{21}^{1} \Psi\right) f .
\end{aligned}
$$

In the above equation, Lemma 7 is used in the first and fourth equality. All limits are in $L^{2}\left(\mu_{2}\right)$ and are justifiable by (8). Since $X_{21}^{1} \Psi \neq 0 \mu_{2}$-a.e., it follows that $X_{21}^{1} Y f=f$.

To finish the proof note that $S_{1}$ and $T=S\left(K, \mu_{1}+\mu_{2}\right)$ are similar via $W: R^{2}\left(K, \mu_{1}\right) \rightarrow R^{2}\left(K, \mu_{1}+\mu_{2}\right)$, where $W r=r$ for all $r$ in Rat $K$. Since $Z: R^{2}\left(K, \mu_{1}+\mu_{2}\right) \cap L^{\infty}\left(\mu_{1}+\mu_{2}\right) \rightarrow R^{2}\left(K, \mu_{2}\right) \cap L^{\infty}\left(\mu_{2}\right)$ defined by $Z f=f$ is weak* continuous, it follows from Proposition 3 that $\Lambda=Z W \mid R^{2}\left(K, \mu_{1}\right) \cap L^{\infty}\left(\mu_{1}\right)$ is also weak* continuous.

The proof of Theorem 1 can now be given. By Proposition 2 and the Simplification Theorem, there exist measures $\mu_{i}(i=1,2)$ such that $S_{i}$ and $S\left(\sigma\left(S_{i}\right), \mu_{i}\right)$ are unitarily equivalent and $\left\{S\left(\sigma\left(S_{i}\right), \mu_{i}\right)\right\}^{\prime}$ satisfy the conclusion of the Simplification Theorem. An application of Proposition 3 completes the proof.

\section{REFERENCES}

[1] W. S. Clary, Equality of spectra of quasi-similar hyponormal operators, Proc. Amer. Math. Soc., 53 (1975), 88-90.

[2] _ Quasi-similarity and subnormal operators, Ph.D. thesis, University of Michigan, 1973.

[3] J. B. Conway, On quasisimilarity for subnormal operators, Illinois J. Math., 24 (1980), 689-702.

[4] _ Subnormal Operators, Pitman Publishing Inc., Marshfield, Mass., 1981.

[5] T. B. Hoover, Quasisimilarity of operators, Illinois J. Math., 16 (1972), 678-686.

[6] M. Raphael, Quasisimilarity and essential spectra for subnormal operators, Indiana Univ. Math. J., 31, No. 2 (1982), 243-246.

Received June 1, 1984.

UNIVERSITY OF MISSOURI

ROLLA, MO 65401 


\section{PACIFIC JOURNAL OF MATHEMATICS EDITORS}

\author{
V. S. VARAdarajan (Managing Editor) \\ University of California \\ Los Angeles, CA 90024 \\ Hebert Clemens \\ University of Utah \\ Salt Lake City, UT 84112 \\ Charles R. DePrima \\ California Institute of Technology \\ Pasadena, CA 91125
}

R. FINN

Stanford University

Stanford, CA 94305

HeRManN FLASChKa

University of Arizona

Tucson, AZ 85721

RAMESH A. GANGOlli

University of Washington

Seattle, WA 98195

ROBION KIRBY

University of California

Berkeley, CA 94720

\author{
C. C. MOORE \\ University of California \\ Berkeley, CA 94720 \\ H. SAMELSON \\ Stanford University \\ Stanford, CA 94305 \\ HAROLD STARK \\ University of California, San Diego \\ La Jolla, CA 92093
}

\section{ASSOCIATE EDITORS}

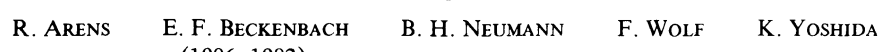

(1906-1982)

\section{SUPPORTING INSTITUTIONS}

\begin{abstract}
UNIVERSITY OF ARIZONA
UNIVERSITY OF BRITISH COLUMBIA

CALIFORNIA INSTITUTE OF TECHNOLOGY

UNIVERSITY OF CALIFORNIA

MONTANA STATE UNIVERSITY

UNIVERSITY OF NEVADA, RENO

NEW MEXICO STATE UNIVERSITY

OREGON STATE UNIVERSITY
\end{abstract}

\author{
UNIVERSITY OF OREGON \\ UNIVERSITY OF SOUTHERN CALIFORNIA \\ STANFORD UNIVERSITY \\ UNIVERSITY OF HAWAII \\ UNIVERSITY OF TOKYO \\ UNIVERSITY OF UTAH \\ WASHINGTON STATE UNIVERSITY \\ UNIVERSITY OF WASHINGTON
}

The Supporting Institutions listed above contribute to the cost of publication of this Journal, but they are not owners or publishers and have no responsibility for its content or policies.

Mathematical papers intended for publication in the Pacific Journal of Mathematics should be in typed form or offset-reproduced (not dittoed), double spaced with large margins. Please do not use built up fractions in the text of the manuscript. However, you may use them in the displayed equations. Underline Greek letters in red, German in green, and script in blue. The first paragraph must be capable of being used separately as a synopsis of the entire paper. In particular it should contain no bibliographic references. Please propose a heading for the odd numbered pages of less than 35 characters. Manuscripts, in triplicate, may be sent to any one of the editors. Please classify according to the scheme of Math. Reviews, Index to Vol. 39. Supply name and address of author to whom proofs should be sent. All other communications should be addressed to the managing editor, or Elaine Barth, University of California, Los Angeles, California 90024.

There are page-charges associated with articles appearing in the Pacific Journal of Mathematics. These charges are expected to be paid by the author's University, Government Agency or Company. If the author or authors do not have access to such Institutional support these charges are waived. Single authors will receive 50 free reprints; joint authors will receive a total of 100 free reprints. Additional copies may be obtained at cost in multiples of 50 .

The Pacific Journal of Mathematics is issued monthly as of January 1966. Regular subscription rate: $\$ 190.00$ a year (5 Vols., 10 issues). Special rate: $\$ 95.00$ a year to individual members of supporting institutions.

Subscriptions, orders for numbers issued in the last three calendar years, and changes of address should be sent to Pacific Journal of Mathematics, P.O. Box 969, Carmel Valley, CA 93924, U.S.A. Old back numbers obtainable from Kraus Periodicals Co., Route 100, Millwood, NY 10546.

The Pacific Journal of Mathematics at P.O. Box 969, Carmel Valley, CA 93924 (ISSN 0030-8730) publishes 5 volumes per year. Application to mail at Second-class postage rates is pending at Carmel Valley, California, and additional mailing offices. Postmaster: Send address changes to Pacific Journal of Mathematics, P.O. Box 969, Carmel Valley, CA 93924.

PUBLISHED BY PACIFIC JOURNAL OF MATHEMATICS, A NON-PROFIT CORPORATION

Copyright $\odot 1986$ by Pacific Journal of Mathematics 


\section{Pacific Journal of Mathematics}

\section{Vol. 122, No. 2 \\ February, 1986}

Gideon Amit and David Chillag, On a question of Feit concerning character values of finite solvable groups ......................257

Constantin Gelu Apostol and Frank Larkin Gilfeather, Isomorphisms modulo the compact operators of nest algebras ................263

Parviz Azimi and James Neil Hagler, Examples of hereditarily $l^{1}$ Banach

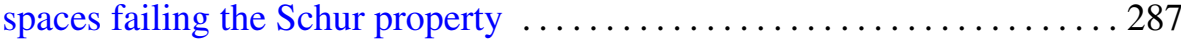

Brian Evan Blank, Boundary behavior of limits of discrete series representations of real rank one semisimple groups . . . . . . . . . . 299

Jeffrey Carroll, Some undecidability results for lattices in recursion theory

Gerald Howard Cliff and Alfred Rheinhold Weiss, Crossed product and

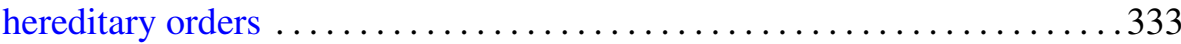

Ralph Cohen, Realizing transfer maps for ramified coverings . . . . . . . . 347

Ronald James Evans, Hermite character sums . .................. 357

C. L. Frenzen and Roderick Sue-Chuen Wong, Asymptotic expansions of the Lebesgue constants for Jacobi series . . . . . . . . . . . . . . . . 391

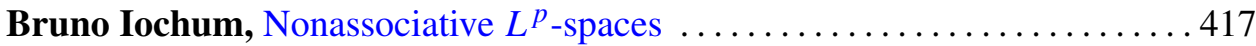

John McDonald, Unimodular approximation in function algebras ....... 435

John Robert Quine, Jr., Ramification and unintegrated value distribution . . 441

Marc Raphael, Commutants of quasisimilar subnormal operators ........ 449

Parameswaran Sankaran and Peter Zvengrowski, On stable

parallelizability of flag manifolds

Helga Schirmer, A relative Nielsen number

Barry Simon, Schrödinger semigroups on the scale of Sobolev spaces . . . . . 475

Viakalathur Shankar Sunder, Stochastic integration in Fock space

Jan de Vries, A note on the $G$-space version of Glicksberg's theorem 